\title{
Aging traits and sustainable trophy hunting of African lions
}

\author{
Authors: Jennifer R.B. Miller, Guy Balme, Peter A. Lindsey a,b, \\ Andrew J. Loveridge, Matthew S. Becker,Colleen Begg, Henry \\ Brink, Stephanie Dolrenry, Jane E. Hunt, Ingela Janssoni, David W. \\ Macdonald, Roseline L. Mandisodza-Chikerema, Alayne Oriol \\ Cotterill, Craig Packer,DanielRosengren, Ken Stratford, Martina \\ Trinkel, Paula A. White, Christiaan Winterbach, Hanlie E.K. \\ Winterbach, and Paul J. Funston
}

NOTICE: this is the author's version of a work that was accepted for publication in Biological Conservation. Changes resulting from the publishing process, such as peer review, editing, corrections, structural formatting, and other quality control mechanisms may not be reflected in this document. Changes may have been made to this work since it was submitted for publication. A definitive version was subsequently published in Biological Conservation, [VOL\# 201, (September 2016)].

DOI\# 10.1016/j.biocon.2016.07.003

Miller, Jennifer R.B., Guy Balme, Peter A. Lindsey, Andrew J. Loveridge, Matthew S. Becker, Colleen Begg, Henry Brink, Stephanie Dolrenry, Jane E. Hunt, Ingela Jansson, David W.

Macdonald, Roseline L. Mandisodza-Chikerema, Alayne Oriol Cotterill, Craig Packer, Daniel Rosengren, Ken Stratford, Martina Trinkel, Paula A. White, Christiaan Winterbach, Hanlie E.K. Winterbach, and Paul J. Funston. "Aging traits and sustainable trophy hunting of African lions." Biological Conservation 201 (September 2106): 160-168. 


\title{
Aging traits and sustainable trophy hunting of African lions
}

\author{
Jennifer R.B. Miller ${ }^{\mathrm{a}, *}$, Guy Balme a, Peter A. Lindsey ${ }^{\mathrm{a}, \mathrm{b}}$, Andrew J. Loveridge ${ }^{\mathrm{c}}$, Matthew S. Becker ${ }^{\mathrm{d}, \mathrm{e}}$, \\ Colleen Begg ${ }^{\mathrm{f}}$, Henry Brink ${ }^{\mathrm{g}}$, Stephanie Dolrenry ${ }^{\mathrm{h}}$, Jane E. Hunt ${ }^{\mathrm{c}}$, Ingela Jansson ${ }^{\mathrm{i}}$, David W. Macdonald ${ }^{\mathrm{c}}$, \\ Roseline L. Mandisodza-Chikerema ${ }^{\mathrm{j}}$, Alayne Oriol Cotterill ${ }^{\mathrm{k}}$, Craig Packer $^{\mathrm{l}}$, Daniel Rosengren ${ }^{\mathrm{m}}$, Ken Stratford $^{\mathrm{n}}$, \\ Martina Trinkel ${ }^{\mathrm{o}}$, Paula A. White ${ }^{\mathrm{p}}$, Christiaan Winterbach ${ }^{\mathrm{q}}$, Hanlie E.K. Winterbach ${ }^{\mathrm{q}}$, Paul J. Funston ${ }^{\mathrm{a}}$ \\ a Panthera, 8 West 40th Street, 18th Floor, New York, NY 10018, USA \\ b Mammal Research Institute, Department of Zoology and Entomology, University of Pretoria, Pretoria, South Africa \\ c Wildlife Conservation Research Unit, Zoology Department, Oxford University, Tubney House, Abingdon OX135QL, UK \\ d Zambian Carnivore Programme, Box 80, Mfuwe, Eastern Province, Zambia \\ e Conservation Biology and Ecology Program, Department of Ecology, Montana State University, 310 Lewis Hall, Bozeman, MT 59717, USA \\ ${ }^{\mathrm{f}}$ Niassa Carnivore Project, The Ratel Trust, Cape Town, South Africa \\ g Selous Lion Project, PO Box 34514, Dar es Salaam, Tanzania \\ h Department of Biological Sciences, Conservation Conflict Research Institute, University of Cape Town, Rondebosch 7701, South Africa \\ ${ }^{i}$ Department of Wildlife, Fish, and Environmental Studies, Swedish University of Agricultural Sciences, SE- 90183 Umeå, Sweden \\ j Zimbabwe Parks and Wildlife Management Authority, PO Box CY140, Causeway, Harare, Zimbabwe \\ ${ }^{k}$ Ewaso Lions, PO Box 14996, Nairobi 00800, Kenya \\ ${ }^{1}$ Department of Ecology, Evolution E'Behavior, University of Minnesota, 100 Ecology Building, 1987 Upper Buford Circle, St. Paul, MN 55108, USA \\ ${ }^{\mathrm{m}}$ Frankfurt Zoological Society, Bernhard-Grzimek-Allee 1, 60316 Frankfurt am Main, Germany \\ n Ongava Research Centre, Ongava Game Reserve, PO Box 58, Okaukeujo, Namibia \\ - School of Biological and Conservation Sciences, University of KwaZulu-Natal, Westville Campus, Private Bag 54001, Durban 4000, South Africa \\ p Center for Tropical Research, Institute of the Environment and Sustainability, University of California Los Angeles, 619 Charles E. Young Drive East, Los Angeles, CA 90095, USA \\ ${ }^{\text {q } C e n t r e ~ f o r ~ W i l d l i f e ~ M a n a g e m e n t, ~ U n i v e r s i t y ~ o f ~ P r e t o r i a, ~ P r e t o r i a, ~ S o u t h ~ A f r i c a ~}$
}

\begin{abstract}
A B S T R A C T
Trophy hunting plays a significant role in wildlife conservation in some contexts in various parts of the world. Yet excessive hunting is contributing to species declines, especially for large carnivores. Simulation models suggest that sustainable hunting of African lions may be achieved by restricting offtakes to males old enough to have reared a cohort of offspring. We tested and expanded criteria for an age-based approach for sustainably regulating lion hunting. Using photos of 228 known-age males from ten sites across Africa, we measured change in ten phenotypic traits with age and found four age classes with distinct characteristics: 1-2.9 years, 3-4.9 years, 56.9 years, and $\geq 7$ years. We tested the aging accuracy of professional hunters and inexperienced observers before and after training on aging. Before training, hunters accurately aged more lion photos (63\%) than inexperienced observers (48\%); after training, both groups improved (67-69\%). Hunters overestimated $22 \%$ of lions $<5$ years as $5-6.9$ years (unsustainable) but only $4 \%$ of lions $<5$ years as $\geq 7$ years (sustainable). Due to the lower aging error for males $\geq 7$ years, we recommend 7 years as a practical minimum age for hunting male lions. Results indicate that age-based hunting is feasible for sustainably managing threatened and economically significant species such as the lion, but must be guided by rigorous training, strict monitoring of compliance and error, and conservative quotas. Our study furthermore demonstrates methods for identifying traits to age individuals, information that is critical for estimating demographic parameters underlying management and conservation of age-structured species.
\end{abstract}

Keywords: Age-based hunting quota Age determination Minimum age threshold Panthera leo Pre-mortem aging Sustainable harvest

\section{Introduction}

Trophy hunting can play a significant role in wildlife conservation by incentivising the conservation of animals and land in exchange for recreational use. In Africa, hunting motivates the retention of vast blocks of state property for wildlife, generates over US\$200 million annually across $>20$ countries, and encourages wildlife-based land uses on large areas of community and private lands (Di Minin et al., 2015; Lindsey et al., 2007; Naidoo et al., 2016). However, poorly managed hunting can negatively affect animal populations by reducing genetic variation, increasing stress levels, changing animal behavior, and driving species decline (Aryal et al., 2015; Burke et al., 2008; Keehner et al., 2015; Packer et al., 2009; Rodríguez-Muñoz et al., 2015). Excessive 
trophy hunting has recently led to localized unsustainable exploitation of ecologically and economically-important species, including elephants (Selier et al., 2014), leopards (Pitman et al., 2015), and lions (Bauer et al., 2015). The negative impacts of hunting in some areas contributed to 'Cecil-gate' in 2015, prompting global public outcry and scrutiny over the use of trophy hunting as a management tool (Di Minin et al., 2015; Lindsey et al., 2016). In light of this recent media spotlight and increasing anthropogenic threats to species, science-based techniques are urgently needed to guide the sustainable management of harvests if trophy hunting is to continue.

Most harvested species, particularly long-lived large mammals, exhibit age and sex specific rates of survival and reproduction (MilnerGulland et al., 2007). Thus, age is a common metric used to guide the sustainable harvest and management of wildlife, including large carnivores, ungulates, and fish (Balme et al., 2012; Bender et al., 1994; Berkeley et al., 2004; Garel et al., 2006; Gipson et al., 2000; Hiller, 2014; Hoefs and Konig, 1984; Lundervold and Langvatn, 2003). Agebased hunting addresses the age-structured nature of populations by harvesting animals at certain age thresholds, which, in combination with conservative quotas, can help reduce negative demographic impacts (Whitman et al., 2004). The success of age-based hunting depends on hunters' abilities to accurately age individuals, and requires traits that indicate relevant age thresholds and are easily discernible in the field. These indicators of age would be equally useful to enforcement authorities for ensuring that trophies meet permitted age thresholds. Because age structure is critical to understanding the dynamics of wildlife populations, determining precise indicators of age at biologically-important life stages is also useful for wildlife research, management and conservation (Delahay et al., 2011; Van Horn et al., 2003). Here we investigate age determination and aging accuracy for African lions in an effort to test the feasibility of using age-based trophy hunting regulations to manage and conserve threatened and economically significant species.

Lions are one of the most highly desired big game trophy species, and ensuring ecological and economic sustainability of lion hunting has been recently prioritised at national and international levels (Lindsey et al., 2013). Lion hunts attract some of the highest mean prices of all trophy species (US\$24,000-125,000 per hunt) and produce 5-17\% of national gross trophy hunting income in countries where lion hunting is allowed (Lindsey et al., 2012, 2007). Yet lion numbers are declining rapidly: the global population has decreased by as much as $42 \%$ over the past 21 years ( 3 generations) to 20,000-35,000 individuals (Bauer et al., 2015; Riggio et al., 2012). In many areas, excessive trophy harvests have contributed to declines in the southern and eastern African subspecies (Groom et al., 2014; Loveridge et al., 2007; Packer et al., 2011, 2009; Rosenblatt et al., 2014). Concerns over lion population decline led Australia and France in 2015-2016 to ban lion trophy imports and resulted in the United States uplisting some lion subspecies to 'Endangered' on the Endangered Species Act (Milman, 2015; U.S. Fish and Wildlife Service, 2015; Vaughan, 2015).

Modelling studies that have assessed the impact of age-based trophy hunting on lion demography indicate that sustainable trophy hunting may be achieved by restricting offtakes to males old enough to have reared their first cohort of offspring, or $\geq 5$ years of age (note that harvesting females is not sustainable; Edwards et al., 2014; Packer et al., 2009; Whitman et al., 2007, 2004). Following these guidelines, Tanzania, Zimbabwe and Niassa National Reserve in Mozambique began implementing age-based hunting restrictions in 2007-2013. In these on-going programmes, age restrictions are paired with quotas revised annually based on compliance with age limits, whereby operators that harvest males equal or older than 5-6 years are 'rewarded' the following year with an equal or higher quota, and operators harvesting males $<4$ 5 years are 'punished' with reduced quotas (age limits vary between countries; Begg and Begg, 2012; Mandisodza et al., 2009; Wildlife Division, 2012). The implementation of age restrictions has resulted in reduced lion quotas and harvests in all three countries in which they have been implemented. Reduced harvests may be due to greater selectivity on the part of hunters, and/or due to the relatively low number of old male lions in hunted populations. Some professional hunters, safari operators, and conservationists have resisted the implementation of age restrictions, citing insufficient scientific evidence for which physical traits are the most reliable indicators of lion age, and disputing the practicality of accurately aging lions in the field.

Age-based hunting systems require simple methods for aging quarry pre-mortem in the field with high precision. In the case of lions, the harvest of younger males ( $<5$ years) has a particularly significant impact due to the removal of individuals before they have raised a litter of cubs to independence and the associated risk of infanticide following the removal of pride males (Whitman et al., 2004). In the countries where age restrictions on lions are in place, lion ages are assessed post-mortem based on teeth size, wear, and development (often using dental radiographs) and skull ossification (using weight and cranial sutures; Ferreira and Funston, 2010a; Smuts et al., 1978; Wildlife Division, 2012). The utility of various potential aging cues pre-mortem is currently less clear. Only one trait has been suggested as a reliable pre-mortem indicator of age: nose pigmentation, which grows darker as lions age (Whitman et al., 2004). However, the correlation between nose pigmentation and age has only been studied in the Serengeti population of lions and doubt has been raised as to whether the relationship holds across Africa (Lindsey et al., 2013). Furthermore, nose darkness can be challenging to assess in the field under varying light and visibility, especially from a distance.

A more practical and effective strategy for aging lions pre-mortem would be to identify a suite of traits that that can be collectively referenced to accurately estimate a lion's age, as has been recently done for leopards (Balme et al., 2012). Because professional hunters often use camera trap photographs to identify animals suitable for trophy hunting, and wildlife managers and researchers use photographs to study individuals and monitor populations, characteristics that are easily identifiable from photographs would be especially useful in aging individuals. Previous studies have identified several candidate traits (Ferreira and Funston, 2010a). Males' manes grow with age, however length can be influenced by injury, testosterone, and nutrition (Smuts, 1980; West and Packer, 2002). Mane colour typically darkens with age but can vary with ambient temperature (West and Packer, 2002; West et al., 2006). Facial scarring and slack jowl also increase with age, with older individuals appearing pockmarked and loose-jowled (Schaller, 1972; Smuts, 1980; West et al., 2006). In order for these traits to be used as reliable indicators of age, the relationship with age should ideally show low variation between individuals and across regions to establish consistent aging guidelines. Furthermore, practitioners should be able to easily grasp associations between traits and age to achieve high aging accuracy.

We aimed to identify distinct phenotypic traits for determining premortem age and to test the utility of these traits for accurately aging male lions. Using an extensive photo dataset of known-age male lions from ten long-term study sites across eastern and southern Africa, we examined associations between physical characteristics and age in a suite of traits between individual lions and across regions. Finally, we tested how accurately practitioners could age lions with varying levels of hunting experience as well as before and after training. We discuss the applicability of our results for use in the conservation and management of harvested large carnivores and their broader implications for the future conservation of lions and other threatened and economically significant species.

\section{Methods}

We collected 601 high resolution photographs ( $\geq 150 \mathrm{dpi}$ ) of 228 known-age male lions (1-16 photos per individual and 92 individuals with $>1$ photo) from ten long-term study sites across eastern and 
southern Africa: the Okavango Delta region $(n=17)$ in Botswana; Kgalagadi Transfrontier Park $(\mathrm{n}=3)$ in Botswana and South Africa; the Amboseli-Tsavo ecosystem $(n=17)$ and Laikipia $(n=2)$ in Kenya; Niassa National Reserve $(n=14)$ in Mozambique; Etosha National Park $(n=3)$ in Namibia; Kruger National Park $(n=29)$ in South Africa; Serengeti National Park $(n=48)$, Selous Game Reserve $(\mathrm{n}=11)$, and Ngorongoro Conservation Area $(\mathrm{n}=21)$ in Tanzania; South Luangwa Valley $(\mathrm{n}=19)$ in Zambia; and Hwange National Park ( $\mathrm{n}=44$ individuals) in Zimbabwe. These sites represent a broad range in elevation (340-1820 m) and climate (arid, warm temperate, and equatorial zones; Fig. 1). Lion populations at these sites have been intensively studied for extended periods. Cubs were typically first seen at 3-8 weeks of age and subsequently identified from natural markings (e.g., whisker spots, ear notches, scars; Packer and Pusey, 1993) and/or through radio collaring. Dates of parturition were estimated from the mother's denning behavior and lactation stains and from physical development in comparison to other cubs of known birthdates (Pusey and Packer, 1994). Only photographs of individuals first viewed at $<3$ months of age were included to enable high precision in aging.

\subsection{Aging traits}

For each photo, author JRBM used sliding scales to score the characteristics of ten phenotypic traits (Table 1): mane development; mane colouration of the chest, neck, shoulder, and forehead; teeth colour and wear; facial scarring; slack jowl; and nose darkness. These traits were known indicators of age in different lion populations (Ferreira and Funston, 2010a; Smuts et al., 1978; West et al., 2006; Whitman and Packer, 2007). Traits were scored in a photo only when they were clearly visible (e.g. teeth traits were scored only in photos of yawning lions). Mane development and colour were assessed using single or paired photos that clearly displayed all upper body parts of the individual.

To test the repeatability of scoring, two naïve observers (graduate students unfamiliar with the study) scored a random subset of 14-50 photos per trait (Balme et al., 2012; Loehr et al., 2008). We compared scores given by students and JRBM using a repeated measures ANOVA with an error term of 'photo/observer' to test for differences between scores in each photo. Student scores were comparable to those given by JRBM, indicating high repeatability (mane development: $F_{2,64}=$

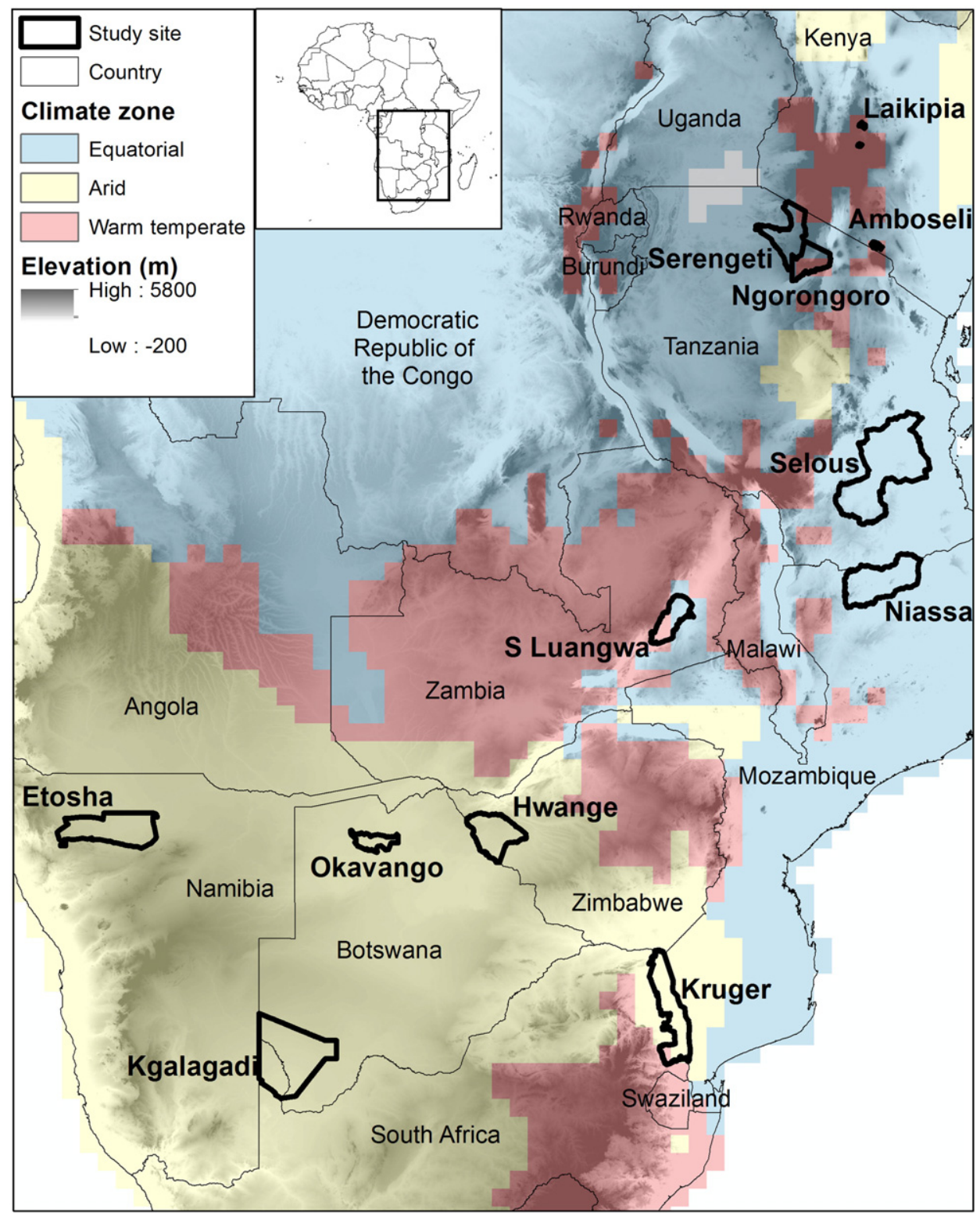

Fig. 1. Map of study sites in Africa with respect to climate zones and elevation. 
Table 1

Score descriptions for the phenotypic traits assessed in known-age male lions.

\begin{tabular}{|c|c|c|}
\hline Trait & $\begin{array}{l}\text { Scoring } \\
\text { code }\end{array}$ & Characteristics \\
\hline \multirow{9}{*}{ Mane development } & 1 & $\begin{array}{l}\text { No or very short hair around face } \\
\text { and on chest and neck }\end{array}$ \\
\hline & 2 & $\begin{array}{l}\text { Short hair around face and on chest } \\
\text { and neck; Mohawk not visible }\end{array}$ \\
\hline & 3 & $\begin{array}{l}\text { Short Mohawk visible; bare patches } \\
\text { between Mohawk and ears }\end{array}$ \\
\hline & & Long Mohawk with bare patches \\
\hline & 4 & $\begin{array}{l}\text { between Mohawk and ears; full } \\
\text { around face and chest; incomplete } \\
\text { on shoulder }\end{array}$ \\
\hline & & Fully developed, with forehead \\
\hline & 5 & $\begin{array}{l}\text { section fully filled between ears; } \\
\text { some growth but mostly incomplete } \\
\text { on shoulder }\end{array}$ \\
\hline & 6 & $\begin{array}{l}\text { Fully developed, with forehead } \\
\text { section fully filled between ears; } \\
\text { shoulders filled in }\end{array}$ \\
\hline & 7 & $\begin{array}{l}\text { Fully developed but thinning; the } \\
\text { end of the hair looks fuzzy or frayed } \\
\text { and/or the mane may thin or fall out } \\
\text { in sections }\end{array}$ \\
\hline \multirow{5}{*}{$\begin{array}{l}\text { Chest, neck, shoulder and } \\
\text { forehead mane darkness } \\
\text { (independent score for each) }\end{array}$} & 1 & Blonde \\
\hline & 2 & Light brown \\
\hline & 3 & Dark brown \\
\hline & 4 & Black \\
\hline & 1 & White \\
\hline \multirow[t]{3}{*}{ Teeth colour } & 2 & Light yellow \\
\hline & 3 & Dark yellow \\
\hline & 1 & No wear (sharp) \\
\hline \multirow{2}{*}{ Teeth wear } & 2 & Slightly worn or chipped \\
\hline & 3 & $\begin{array}{l}\text { Heavily worn, very flat and very } \\
\text { chipped }\end{array}$ \\
\hline \multirow{3}{*}{ Facial scarring } & 1 & Unscarred \\
\hline & 2 & Lightly scarred or pocked \\
\hline & 3 & Heavily scarred or pocked \\
\hline \multirow{2}{*}{ Slack jowl } & 1 & $\begin{array}{l}\text { Absent: lower and upper lips tightly } \\
\text { meet when mouth closed (not } \\
\text { drooping) }\end{array}$ \\
\hline & 2 & $\begin{array}{l}\text { Present: lower lip obviously droops } \\
\text { apart from top lip and downward } \\
\text { when mouth closed }\end{array}$ \\
\hline \multirow{11}{*}{ Nose darkness } & $0 \%$ & No black, all pink \\
\hline & $10 \%$ & Between 0 and $10 \%$ black \\
\hline & $20 \%$ & Between 10 and $20 \%$ black \\
\hline & $30 \%$ & Between 20 and $30 \%$ black \\
\hline & $40 \%$ & Between 30 and $40 \%$ black \\
\hline & $50 \%$ & Between 40 and $50 \%$ black \\
\hline & $60 \%$ & Between 50 and $60 \%$ black \\
\hline & $70 \%$ & Between 60 and $70 \%$ black \\
\hline & $80 \%$ & Between 70 and $80 \%$ black \\
\hline & $90 \%$ & Between 80 and $90 \%$ black \\
\hline & $100 \%$ & All black, no pink \\
\hline
\end{tabular}

2.352, $P=0.103$; chest mane colour: $F_{2,64}=0.267, P=0.767$; neck mane colour: $F_{2,64}=2.596, P=0.082$; shoulder mane colour: $F_{2,64}=$ $0.195, P=0.823$; forehead mane colour: $F_{2,64}=0.209, P=0.812$; slack jowl: $\mathrm{F}_{2,60}=1.000, P=0.374$; teeth colour: $\mathrm{F}_{2,26}=1.560, P=$ 0.229 ; teeth wear: $F_{2,26}=1.368, P=0.272$; facial scarring: $F_{2,56}=$ $1.314, P=0.277$; nose darkness: $\mathrm{F}_{2,96}=2.731, P=0.070$ ).

A previous study had found a correlation between nose darkness and age by digitally quantifying the proportion of black pigmentation pixels in the nose (Whitman et al. 2004). To test whether digital assessment differed from human scoring by eye, we additionally measured nose darkness with a similar digital method. Using Adobe Photoshop CS6 v.13.0.6, we clipped the fleshy part of the nose in each photo and set the colour value threshold to differentiate between the 'black' versus 'not black' ( pink) portions of the nose. We then used the histogram tool to calculate the percentage of black nose pixels. To determine whether nose darkness differed by age between measurements made 'by eye' and digitally, we ran a Pearson correlation and tested whether values were comparable for each photo using a repeated measures ANOVA.

We examined the age associated with scores for each trait using ANOVA with Tukey post-hoc tests to see which scores significantly differed by age range. To identify which characteristics within a trait could be used to determine age, we grouped together adjacent score categories when doing so produced significantly different age classes. For example, we initially measured nose darkness with 11 categories $(0 \%$, $10 \%, \ldots 90 \%, 100 \%$ black) but some of these categories (e.g. $0 \%$ and $10 \%$ ) did not differ significantly in age. In these cases, non-significance indicated natural variation in the trait within an age and we grouped the adjacent score categories into a single group for analysis (e.g. 0$10 \%$ ). To test how well each trait predicted age, we used linear mixed effects models to model 'age' by 'trait score' (fixed effect) with a random intercept effect of 'site' and 'individual' within each site ('site/individual' in the model) to account for pseudo-replication due to the availability of multiple photographs for some individuals and for the clustering of individuals with sites. We assessed model fit using the conditional $\mathrm{R}^{2}$, a standard metric which describes the proportion of variance explained by both the fixed and random factors (Johnson, 2014). We additionally investigated how mane colouration changed with age by body part. We did this by running ANOVA tests on scores by age, with age grouped into 1 -year age classes, and compared colouration scores by body part. All traits data were normally distributed.

We also explored whether trait development varied for lions in different geographical regions and climates. In particular, mane development and colour have been suggested to vary regionally and with temperature and humidity (West and Packer, 2002). We therefore tested how traits varied with elevation (data from the CGIAR-CSI SRTM; Jarvis et al., 2008) and climate zone (Koppen-Geiger Climate Classification, major zone; Kottek et al., 2006). Regional variable values were calculated as the mean of pixels within each study site boundary (data from The World Database on Protected Areas; IUCN and UNEP-WCMC, 2015) using zonal statistics in ArcGIS (Table A1). We added the interaction term 'trait score' * 'regional variable' to the previous linear mixed effects models and ran Chi-square tests to determine whether the regional variable significantly improved the model. Effects of regional variation were tested for all traits except slack jowl and facial scarring due to uneven sample sizes across regions. All statistical tests were run in $\mathrm{R}$ v.3.1.3 (R Development Core Team 2008).

\subsection{Aging accuracy}

A subset of known-age male lion photos was used to measure the effectiveness of training with phenotypic traits on improving accuracy in aging lions. We tested accuracy levels before and after training using a survey consisting of three sections: (1) a "pre-test", where participants aged individuals in 32 photos based on their baseline knowledge of lions; (2) a training, where participants reviewed brief educational materials on the traits for recognising lion age (based on the traits analysis); and (3) a "post-test", where participants aged individuals in 32 different photos. Participants were asked to assign the lions in photos to one of four age classes: (1) 1-2.9 years, (2) 3-4.9 years, (3) 56.9 years, and $(4) \geq 7$ years. Because participants' ability to distinguish between the middle two age classes (3-4.9 years and 5-6.9 years) have the greatest implications for sustainable trophy hunting, to reduce variance we included in each section ten photos for each of the middle age classes and six photos for each the youngest and oldest age classes. Most traits were visible in all photos except for teeth colour and wear, which were not included in the survey assessment or training because photos with these traits excluded most other traits (e.g. featured only the mouth).

We conducted the anonymous survey online with two groups: professional hunters, who are responsible for determining which individual lions are suitable for clients to harvest, and inexperienced observers (college students), who offered a baseline for comparison against 

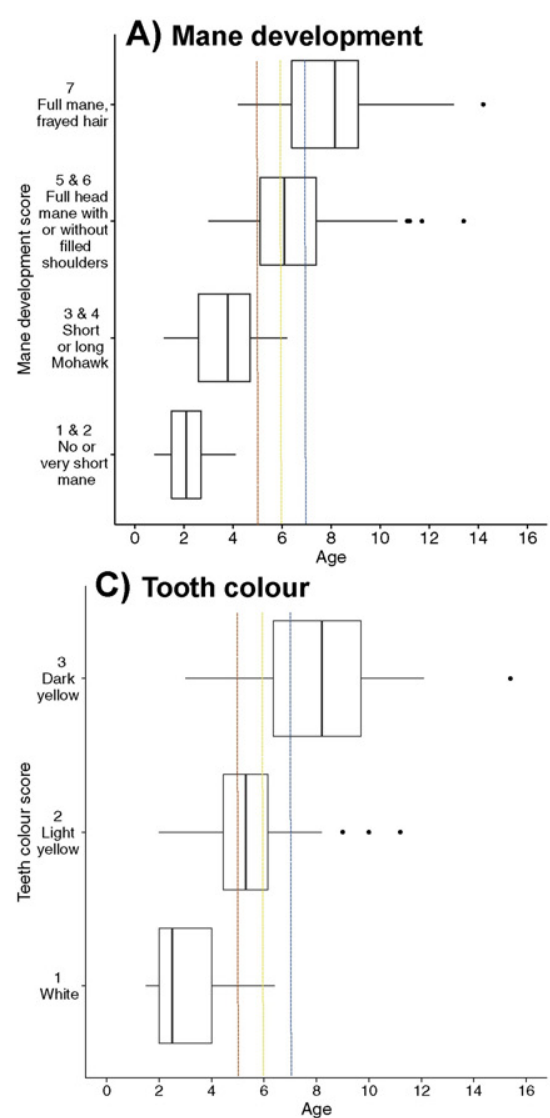

E) Facial scarring
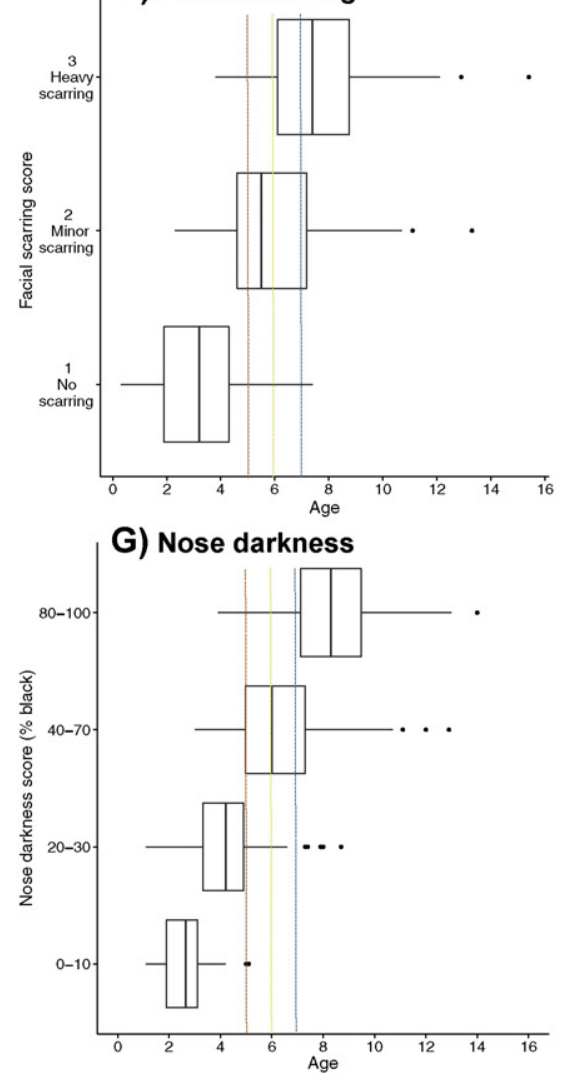

B) Mane colour

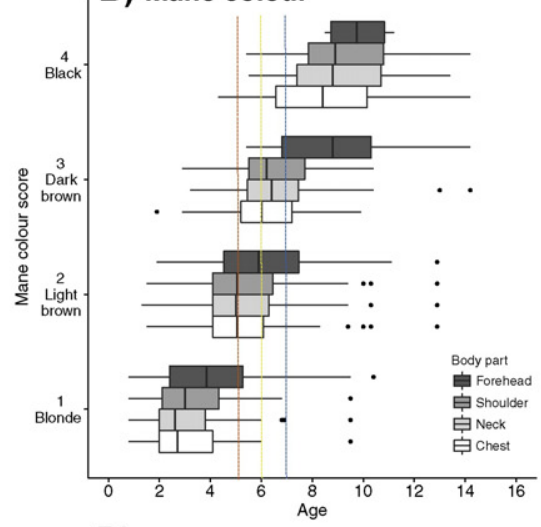

D) Tooth wear

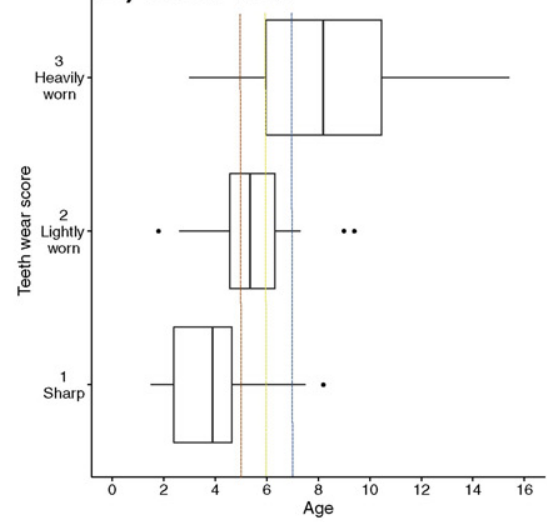

F) Slack jowl

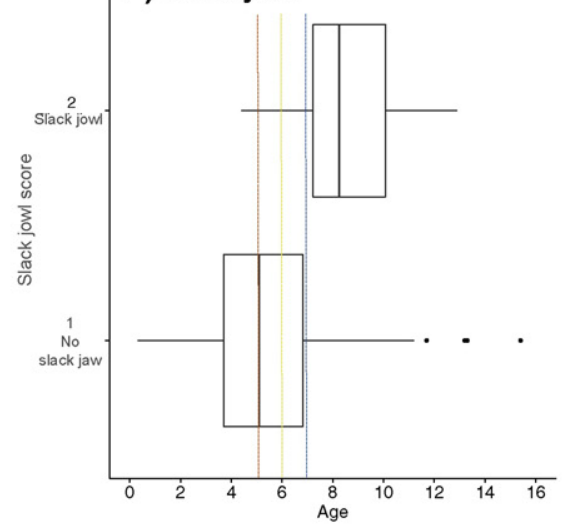

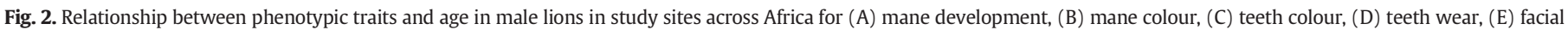

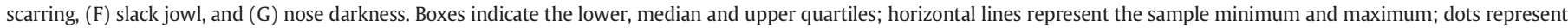

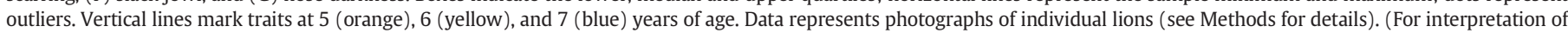
the references to colour in this figure legend, the reader is referred to the web version of this article.) 
hunters. To explore how experience influenced participants' accuracy in aging, we asked both students and hunters how many hunts (any species) they had participated in and whether they had previously received education on aging lions. We additionally asked hunters how many years they had worked as professional hunters, how many lion hunts they had attended, and whether they had previously participated in a lion hunt that followed age restrictions. We included these data as predictor variables in multivariate linear regressions with a response variable of aging accuracy score for each participant group before and after training. We calculated each participant's aging accuracy score for the pre- and post-test sections as the percentage of correctly aged photos. We compared scores between sections and participants using unpaired and paired t-tests with equal variances, respectively. We also examined which lion ages were most often categorised accurately by calculating the mean percentage of photos assigned to each of the four age classes and used ANOVA to compare differences by age class.

\section{Results}

\subsection{Aging traits}

For all ten phenotypic traits, age was strongly predicted by score (statistics below) and varied across scores (Fig. 2; mane development: $\mathrm{F}_{6,210}=37.17, P<0.001$; chest mane colour: $F_{3,213}=68.30, P<0.001$; neck mane colour: $F_{3,213}=55.19, P<0.001$; shoulder mane colour: $\mathrm{F}_{3,213}=65.77, P<0.001$; forehead mane colour: $\mathrm{F}_{3,213}=44.45$, $P<0.001$; teeth colour: $F_{2,90}=33.82, P<0.001$; teeth wear: $F_{2,90}=$ 36.72, $P<0.001$; facial scarring: $F_{2,189}=59.47, P<0.001$; slack jowl: $F_{1,208}=22.21, P<0.001$; nose darkness [by eye]: $F_{10,306}=41.17$, $P<0.001)$. Traits showed overlap in the ages associated with some scores, especially for mane development and nose darkness. Post-hoc analyses revealed that compiling mane and nose darkness scores each into four categories of characteristics produced significantly distinct age classes between scores $(P<0.006$ and $P<0.0002$, respectively; Fig. 2A, Fig. $2 G$ ); all other traits showed significant differences in age between scores without grouping $(P<0.01$; except mane forehead colour between dark brown and black, $P=0.858$ ). Four age classes could be distinguished based on the revised grouping of trait characteristics: 12.9 years, $3-4.9$ years, $5-6.9$ years, and $\geq 7$ years.

By age class, the majority of males ( $\geq 50 \%) 1-2.9$ years of age were characterised by a smooth face (no facial scarring), tight jowl (no slack jowl), no mane or a small Mohawk, blonde hair colour on the chest, neck, shoulder, and forehead, sharp white teeth, and nose darkness of $0-30 \%$ black (Fig. 2). Most males 3-4.9 years showed a smooth face or light facial scarring, tight jowl, large Mohawk or full mane, blonde or light brown hair colour on the chest, neck, shoulder, and forehead, sharp or lightly worn light yellow teeth, and nose darkness of 20$60 \%$ black. Males 5-6.9 years predominantly showed light facial scarring, tight jowl, full mane, light or dark brown mane colour on the chest, neck, shoulder, and forehead, lightly or heavily worn light yellow teeth, and nose darkness of $40-70 \%$ black. Most males $\geq 7$ years showed light or heavy facial scarring, full mane with or without fraying hair, black mane colour on the chest, neck, shoulder and forehead, lightly or heavily worn dark yellow teeth, nose darkness of $40-100 \%$ black, and a tight jowl. Jowl slackness was a unique identifying characteristic for the oldest age class: though only $24 \%$ of lions $\geq 7$ years old showed slack jowls, $73 \%$ of individuals with slack jowls were $\geq 7$ years old (Table A2).

Trait score, but not elevation or climate zone, was a significant predictor of ages associated with mane development (score: $t_{196}=$ $14.338, P<0.001, \mathrm{R}^{2}=0.73 ; P>0.4$ for all Chi-square tests with regional variables) and colour (chest: $\mathrm{t}_{214}=13.963, P<0.001, \mathrm{R}^{2}=0.74$; neck: $\mathrm{t}_{216}=12.386, P<0.001, \mathrm{R}^{2}=0.70$; shoulder: $\mathrm{t}_{216}=13.747, P<0.001$, $\mathrm{R}^{2}=0.73$; forehead: $\mathrm{t}_{216}=9.865, P<0.001, \mathrm{R}^{2}=0.55 ; P>0.3$ for all Chi-square tests), nose darkness ( $t_{306}=18.704, P<0.001, R^{2}=0.78$; $P>0.20$ for all Chi-square tests $)$, and teeth colour $\left(t_{76}=7.749\right.$,

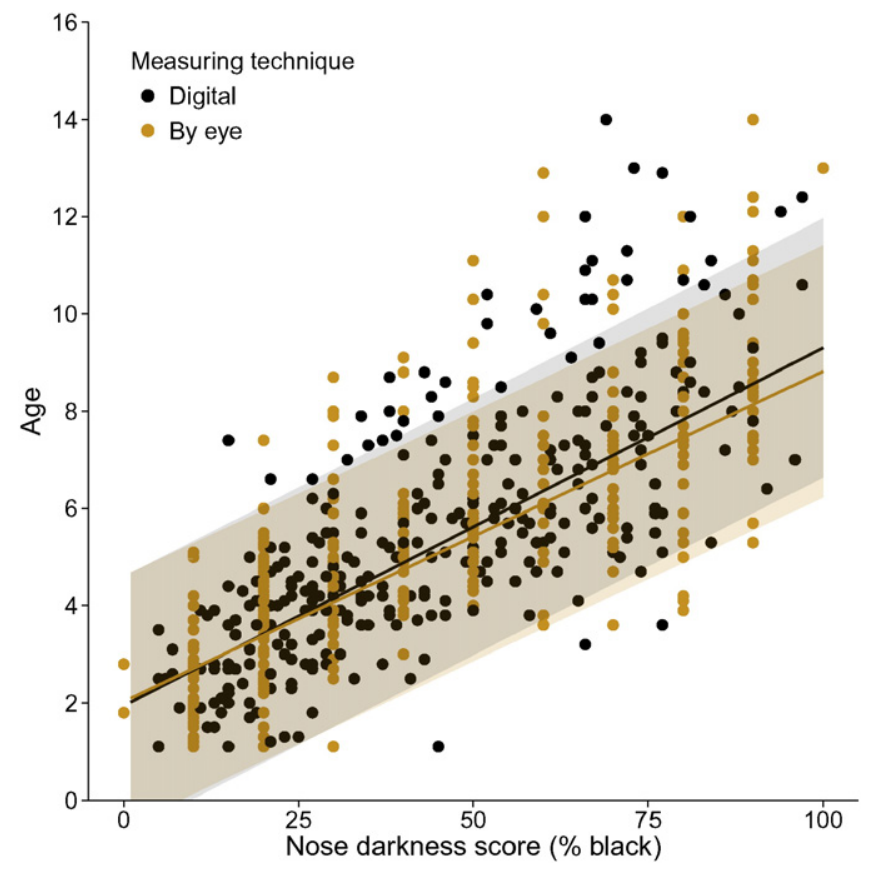

Fig. 3. Differences in nose darkness with age by measuring technique. Each point represents a different photograph of an individual lion; in some cases (64 out of $n=$ 138 individuals), the same individual was measured at multiple ages. Lines represent linear mixed model predictions; shaded ribbons represent $95 \%$ prediction intervals (orange $=$ by eye; grey $=$ digital).

$P<0.001, \mathrm{R}^{2}=0.62 ; P>0.07$ for all Chi-square tests) and wear ( $\mathrm{t}_{77}=7.765, P<0.001, \mathrm{R}^{2}=0.60 ; P>0.4$ for all Chi-square tests). Assessments of nose darkness made by eye and digital methods were statistically correlated $\left(r=0.825, \mathrm{t}_{315}=25.938, P<0.001\right)$ and numerically equivalent $\left(F_{1,316}=0.367, P=0.545\right.$; Fig. 3$)$. Though not statistically significant, we observed differences in mane development by climate. Lion manes appear to grow more slowly and sparsely at sites in the equatorial climate zone (Selous and Niassa) than in warm temperate or arid climates, causing these individuals to resemble lions 2-3 years younger than same-aged individuals in other sites (Fig. S1).

\subsection{Aging accuracy}

Fifty-three professional hunters and 52 students completed the survey. Hunter participants averaged 16 years of professional hunting experience (range of 1-40 years) in numerous African countries, primarily Tanzania (45\%), Zimbabwe (45\%), South Africa (30\%), Namibia $(21 \%)$, Zambia (19\%) and/or Mozambique (17\%; note that most hunters worked in more than one country). Nearly all hunters (92\%) had previously participated in a lion hunt, with $42 \%$ having attended $>20$ lion hunts, and $62 \%$ had attended lion hunts with age restrictions on harvested individuals. However, less than half (43\%) had previously received education (participated in a training or read educational materials) on aging lions. The majority of students had never participated in a wildlife hunt (65\%) and had never received education on aging lions (90\%).

Professional hunters scored significantly higher than students before training (mean percent of correctly aged photos for hunters $=63 \pm 2 \%$ [standard error], range of $38-78 \%$; students $=48 \pm 2 \%$, range $22-78 \%$; $\left.\mathrm{t}_{103}=-5.897, P<0.001\right)$ and similarly to students after training (hunters: $69 \pm 1 \%$, range $44-84 \%$; students: $67 \pm 2 \%$, range $38-88 \%$; $\left.\mathrm{t}_{103}=-0.783, P=0.435\right)$. Paired $\mathrm{t}$-tests revealed that both hunters and students scored higher after training $\left(t_{52}=-3.274, P=0.002\right.$ and $t_{51}=-8.129, P<0.001$, respectively). Students improved significantly more than hunters $\left(\mathrm{t}_{103}=4.350, P<0.001\right)$, increasing their accuracy by an average of $19 \pm 2$ percentage points compared to $6 \pm 2$ for 


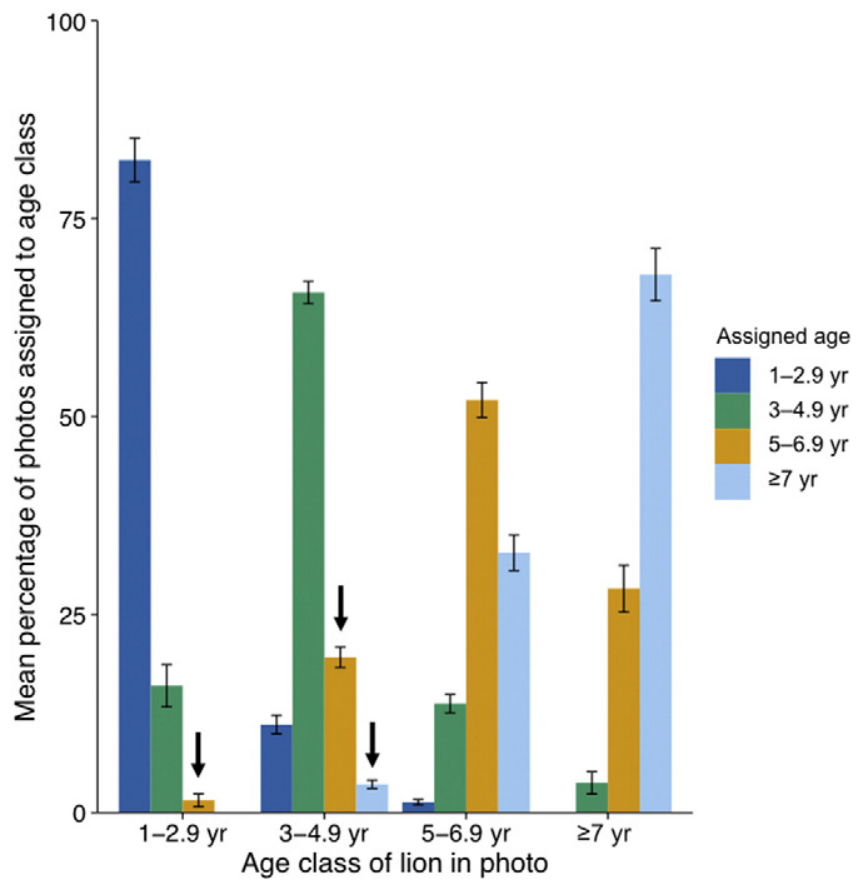

Fig. 4. Mean percentage of male lion photos assigned to different age classes by professional hunters compared to the actual age of the lion photo. Correctly aged lion photos are indicated where the assigned age (colour) matches the age class of the lion photo ( $\mathrm{x}$-axis). Arrows indicate lions $<5$ years that were overestimated as $\geq 5$ years (unsustainable harvest). Bars indicate standard error ( $n=53$ participants).

hunters. Linear regression found no associations between aging accuracy and experience variables for either hunters or students before $\left(\mathrm{F}_{8,44}=1.282\right.$, adjusted $\mathrm{R}^{2}=0.042, P=0.278 ; F_{4,47}=3.197$, adjusted $\mathrm{R}^{2}=0.147, P=0.021$, respectively $)$ or after training $\left(\mathrm{F}_{8,44}=1.539\right.$, adjusted $\mathrm{R}^{2}=0.077, P=0.172 ; F_{4,47}=2.532$, adjusted $\mathrm{R}^{2}=0.107, P=$ 0.527 , respectively).

The percentage of lions accurately aged assigned by hunters after training significantly differed among all age classes except 3-4.9 years and $\geq 7$ years $\left(F_{3,208}=24.350, P<0.001\right.$; Tukey post-hoc $P=0.920$, $P<0.001$ for all other pairs). Hunters most accurately aged $1-2.9$ yearold lions (82\% correct) and least accurately aged $5-6.9$ year-old lions (52\%); 3-4.9 year-olds and $\geq 7$ year-olds were aged with $67 \%$ and $68 \%$ accuracy, respectively (Fig. 4). Hunters overestimated the age of $20 \%$ of 3-4.9 year-olds and $2 \%$ of $1-2.9$ year-olds by mis-categorising photos as $5-6.9$ years, and $4 \%$ of $3-4.9$ year-olds as $\geq 7$ years. Hunters underestimated the age of $15 \%$ of $5-6.9$ year-olds and $4 \%$ of $\geq 7$ yearolds by mis-categorising photos as $<5$ years old.

\section{Discussion}

The ability to age individual animals in wildlife populations is necessary for informed wildlife management and conservation as well as sustainable, age-selective hunting of threatened, high-valued species. Our study revealed a suite of phenotypic traits in African lions that conspicuously change with age at biologically meaningful intervals. Most of these traits are consistent across regions, and can be used pre-mortem to categorise individuals by age class with a moderate to high degree of accuracy. Most importantly, these traits do help in distinguishing the minimum age threshold of $\geq 5$ years recommended for sustainable harvest of lions (Whitman et al., 2004). However, our results revealed that a large proportion ( $22 \%$ ) of 'underage' lions ( $<5$ years) were mistakenly overestimated to be 5-6.9 year-olds, or suitable for hunting according to current age-based hunting systems in several African countries. This high error rate in critical age classes should be further investigated and suggests that an older minimum age threshold (e.g. $\geq 7$ years) may be a more practical threshold for achieving sustainable harvests.

We found that that no single trait can be relied upon exclusively to precisely age lions; rather, multiple traits must be examined in combination to cross-validate an individual's age. For example, our findings corroborate previous evidence that nose darkness can be used for aging following the " $50 \%$ rule" (lions with noses $\geq 50 \%$ black are on average $\geq 5$ years; Whitman et al., 2004) by the human eye (in addition to digital measurement). Yet nose darkness showed such high variation around this age threshold ( $25 \%$ of lions with noses $\geq 50 \%$ black were $<5$ years old and $10 \%$ were $<4$ years old) such that nose darkness should not be used as alone to estimate age. Referring to nose darkness as well as mane development, facial scarring, and teeth colour and wear will account for age variation within each trait and improve the accuracy of age assessment. An exception is slack jowl, which was a strong indicator of older lions when present, although only one-third of lions $\geq 7$ years old showed slack jowls. Due to large overlap in mane colour among ages, we did not find this trait to be useful for precisely determining age.

Based on synchronised development across the suite of phenotypic traits, we were able to categorise lions into four age classes that also corresponded to important biological stages of development: 12.9 years (dependent and non-reproductive), $3-4.9$ years (independent and beginning to reproduce), 5-6.9 years (prime reproductive age), $\geq 7$ years (final reproductive years and past-prime, non-reproductive). For carnivores and lions in particular, precisely estimating an animal's age is necessary for assessing population demographic parameters, such as survival and reproduction, to manage and conserve species. Thus, in addition to assisting hunters, these classes may be especially informative to wildlife researchers and managers for assessing individual behavior and population structure.

Surprisingly, we did not find statistically significant regional variation in mane development or colour by age. This contrasts with previous studies that have documented shorter length, lower density, and slower growth rates as well as blonder colour in the manes of lions living at warmer and more humid climates (Kays and Patterson, 2002; Patterson et al., 2006; West and Packer, 2002; Fig. A1). We attribute this result to our small sample size of mane photos from sites in the equatorial climate zone $(n=6$ compared to $n=103$ from arid and $\mathrm{n}=108$ from warm temperate zones). If our sample size for this climate zone had been larger, we suspect that our results would have mirrored the findings of previous studies. Consequently, in sites where manes are short and sparse, such as Selous and Niassa, we recommend that other traits in addition to mane development be used for aging lions.

Accuracy survey results suggest that, with rigorous training, people with varying levels of experience can use phenotypic traits to accurately age lions. Both inexperienced observers and hunters improved their accuracy scores after training, with inexperienced observers scoring on par with hunters. The fact that both hunters and inexperienced observers scored similarly after training suggests a proficiency threshold, after which more intense training is necessary to improve; however, this threshold is likely test-specific (e.g. dependent on the number and quality of photos). Hunters improved only $6 \%$ after training, emphasizing a need for a more rigorous training than our survey provided. Considering that the online training was self-administered, computerbased, and brief (10 min), participants would likely further improve their accuracy through a more comprehensive, interactive, and fieldbased training. The need for adequate training cannot be stressed enough, as the success of age-based hunting is fundamentally dependent on hunters' abilities to accurately age. Until a rigorous training program which raises hunters' aging accuracy to acceptable levels (which must also be determined by management authorities) can be developed, quotas and minimum age thresholds must account for large margins of error. Our finding that previous experience with hunting or aging did not improve participants' lion aging abilities aligns with previous findings from a similar aging assessment of African leopards (Balme et al., 2012). 
Hunters were least successful in aging lions in the 5-6.9 year age class, the most important age threshold for sustainable lion offtake. Hunters mis-categorised and overestimated $24 \%$ of $3-4.9$ year-old lions to be of suitable hunting age ( $\geq 5$ years), which in the field would have resulted in unsustainable harvest. Notably, hunters also underestimated $15 \%$ of photos of $5-6.9$ year-olds and $4 \%$ of $\geq 7$ yearolds as ages unsuitable for sustainable hunting, which could benefit lion conservation by allowing these males in their prime reproductive stage to sire additional offspring. The effects of such aging errors on lion demography and conservation have not been well studied (Whitman et al., 2007). Government agencies may wish to consider raising the minimum age threshold to $\geq 7$ years as a more assured way of achieving sustainability by accounting for aging error. The traits that characterise $\geq 7$ year-old lions are more unique and distinct than those associated with younger age classes, and although some 56.9 year old lions were mis-categorised as $\geq 7$ year-old and vice-versa, very few 'underage' lions ( $<5$ years) were mis-categorised as $\geq 7$ years (4\%). This suggests that setting a minimum age threshold of 7 years would be more likely to achieve sustainable rates of hunting because individuals that are inaccurately aged would be mistaken as $\geq 5$ years, the minimum age for sustainable offtake assuming no effect of aging error (Whitman et al., 2004). Lions $\geq 7$ years old are also more likely to have successfully reproduced and raised at least one litter to maturity, thus reducing the impacts of infanticide (Bertram, 1975; Packer, 2001). Finally, this threshold is in line with emerging evidence that $\geq 7$ years is a more sustainable minimum harvest age for lions in some parts of Africa (Creel et al., 2016). If 7 years were legally set as a minimum threshold, a simple rule could be to restrict harvest to lions with slack jowls or to lions with majority-black noses ( $>60 \%$ black), heavy facial scarring, and dark yellow and heavily worn teeth (an appearance which could also potentially be more desirable to hunters).

In the age-based quota systems of Mozambique, Tanzania, and Zimbabwe, punishments and rewards based on trophy ages are decided through age validation using post-mortem assessment conducted by wildlife government authorities. Many of these assessments are made based on photographs of the trophy head and side body that are required to be submitted with hunt return forms. The trait characteristics identified in our study (with the exception of slack jowl) could assist authorities in more precisely estimating ages and regulating harvests.

Our results indicate the importance of education and outreach for improving the aging skills of wildlife professionals. We recommend that hunting operators and authorities prioritise - and consider requiring - trainings for professional hunters. Lion aging techniques could be included more widely in the curricula and final examination of hunting courses as a prerequisite for licensing, as is the case in Zimbabwe with lions, in the United States with mountain lions (http://cpw.state.co.us/ thingstodo/Pages/LionExam.aspx, accessed February 2016), and is being developed in South Africa for leopards. Several lion aging guides have already been produced (Whitman and Packer, 2007; Whitman, 2010), and we reiterate the need for simple, user-friendly resources and consistent messaging to improve the aging ability of wildlife professionals. The results of this study have been developed into hardcopy and digital resources which are freely accessible online (http:// AgingTheAfricanLion.org) and are being actively shared with hunting operators and wildlife managers, researchers, and conservation practitioners.

The tractability of age-based hunting systems has ramifications for international policy-level decision-making about lion conservation and the economic markets tied to the hunting industry. Age restrictions and adaptive quota systems that are transparent and properly implemented may offer more realistic and attainable metrics for sustainability than wildlife population assessments (Creel et al., 2016; Whitman et al., 2004). We recommend that agency authorities in market countries, such as the U.S. Fish and Wildlife Service, consider the use of age restrictions and adaptive quota systems for making decisions about trophy imports. Until alternatives to trophy hunting can be found to support conservation (Lindsey et al., 2016), we recommend that these agencies work with range countries to develop and monitor age-based hunting quotas that are adequately conservative to achieve desired conservation goals for each lion population.

The implications of our study also extend beyond hunting and lions. Age determination is a critical component of accurately estimating the demographic parameters (recruitment, survival, dispersal, population size) of wildlife populations for successful conservation and management (Becker et al., 2013; Ferreira and Funston, 2010b; Skalski et al., 2005). Because tracking individual animals is rarely logistically or monetarily feasible, the ability to accurately and non-invasively age from physical appearance may help to interpret social interactions as well as population dynamics. The aging traits identified in our study could be used in numerous applications, including aging individuals involved in research (e.g. animals collared for telemetry or photographed in camera trap surveys), human-wildlife conflict (e.g. captured problem animals), tourism and nature education (e.g. animals seen on safari or in documentaries), and in populations where close monitoring is required due to intense poaching or other pressures. Several of the lion aging traits identified by our study have been relevant for other species, such as African leopards (Balme et al., 2012), European badgers (Delahay et al., 2011), grey wolves (Gipson et al., 2000), and spotted hyenas (Van Horn et al., 2003), and we hope that our methodology will serve as a model for age determination in other species.

The recent illegal killing of 'Cecil the lion' placed an international spotlight on African trophy hunting that questioned the integrity of hunting practices and the future value of hunting for funding conservation (Di Minin et al., 2015; Lindsey et al., 2016). If lion trophy hunting is to continue, practices must at least adhere to science-based regulations and achieve population sustainability. We present practical criteria to support an age-based hunting system for lions that would reduce over-harvest and that could potentially halt the decline of the species in hunted populations. This could benefit hunting operators and professional hunters at multiple scales by assisting compliance with recent international regulations requiring hunting to have a net positive impact on lion populations, by securing the financial stability of trophy hunting (Lindsey et al., 2012) and by improving trophy quality (Whitman et al., 2004). Zimbabwe and Niassa National Reserve in Mozambique, which began implementing age-based lion trophy hunting over the past few years, are reporting successes in the management of lion hunting that include increasing lion trophy age, hunt success, and population size. In demonstrating a reliable toolset for aging, we hope that this study facilitates continued and increasing positive outcomes in these countries as well as others that choose to sustainably manage wildlife for the long-term.

\section{Acknowledgements}

We express our thanks to the hunters and students who participated in our survey and the professional hunters associations who worked to increase participation. Special thanks to N. Fordyce, M. Lewis, N. Okes, and S. Viljoen for assistance with the study. This manuscript benefited from feedback from members of the Cornell University Human Dimensions Graduate Seminar and several anonymous reviewers. Finally, we wish to acknowledge the government agencies, hunting operators, and professional hunters that have embraced and encouraged agebased hunting as a sustainable practice.

\section{Appendix A. Supplementary data}

Supplementary data to this article can be found online at http://dx. doi.org/10.1016/j.biocon.2016.07.003. 


\section{References}

Aryal, A., Dhakal, M., Panthi, S., Yadav, B., Shrestha, U., Bencini, R., Raubenheimer, D., Ji, W., 2015. Is trophy hunting of bharal (blue sheep) and Himalayan tahr contributing to their conservation in Nepal? Hystri http://dx.doi.org/10.4404/hystrix-26.2-11210.

Balme, G.A., Hunter, L.T.B., Braczkowski, A.R., 2012. Applicability of age-based hunting regulations for African leopards. PLoS One 7, 1-9. http://dx.doi.org/10.1371/journal. pone.0035209.

Bauer, H., Chapron, G., Nowell, K., Henschel, P., Funston, P.J., Hunter, L.T.B., Macdonald, D.W., Packer, C., 2015. Lion (Panthera leo) populations are declining rapidly across Africa, except in intensively managed areas. Proc. Natl. Acad. Sci. 112, 14894-14899. http://dx.doi.org/10.1073/pnas.1500664112.

Becker, M.S., Watson, F.G.R., Droge, E., Leigh, K., Carlson, R.S., Carlson, A.A., 2013. Estimating past and future male loss in three Zambian lion populations. J. Wildl. Manag. 77, 128-142. http://dx.doi.org/10.1002/jwmg.446.

Begg, C.M., Begg, K.S., 2012. The status of lions and their threats in Niassa National Reserve, Mozambique. Technical Report Produced for SRN, Maputo.

Bender, L.C., Roloff, G.J., Haufler, J.B., 1994. Antler characteristics as an age discriminator in Michigan elk (Cervus elaphus). Am. Midl. Nat. 132, 401-404.

Berkeley, S.A., Hixon, M.A., Larson, R.J., Love, M.S., 2004. Fisheries sustainability via protection of age structure and spatial distribution of fish populations. Fisheries 29, 23-32. http://dx.doi.org/10.1577/1548-8446(2004)29[23:FSVPOA]2.0.CO;2.

Bertram, B., 1975. Social factors influencing reproduction in wild lions. J. Zool. 177, 463-482.

Burke, T., Page, B., van Dyk, G., Millspaugh, J., Slotow, R., 2008. Risk and ethical concerns of hunting male elephant: behavioural and physiological assays of the remaining elephants. PLoS One 3. http://dx.doi.org/10.1371/journal.pone.0002417.

Creel, S., M'Soka, J., Droge, E., Rosenblatt, E., Becker, M., Matandiko, W., Simpamba, T., 2016. Assessing the sustainability of African lion trophy hunting, with recommendations for policy. Ecol. Appl. http://dx.doi.org/10.1002/eap.1377.

Delahay, R.J., Walker, N., Gunn, M.R., Christie, C., Wilson, G.J., Cheeseman, C.L., Mcdonald, R.A., 2011. Using lifetime tooth-wear scores to predict age in wild Eurasian badgers: performance of a predictive model. J. Zool. 284, 183-191. http://dx.doi.org/10.1111/j. 1469-7998.2011.00796.x

Di Minin, E., Leader-Williams, N., Bradshaw, C.J.A., 2015. Banning trophy hunting will exacerbate biodiversity loss. Trends Ecol. Evol. 2037, 1-4. http://dx.doi.org/10.1016/j. tree.2015.12.006.

Edwards, C.T.T., Bunnefeld, N., Balme, G.A., Milner-Gulland, EJ., 2014. Data-poor management of African lion hunting using a relative index of abundance. Proc. Natl. Acad. Sci. 111, 539-543. http://dx.doi.org/10.1073/pnas.1219615110.

Ferreira, S.M., Funston, P.J., 2010a. Age assignment to individual African lions. S. Afr. J. Wildl. Res. 40, 1-9. http://dx.doi.org/10.3957/056.040.0103.

Ferreira, S.M., Funston, P.J., 2010b. Estimating lion population variables: prey and disease effects in Kruger National Park, South Africa. Wildl. Res. 37, 194-206. http://dx.doi. org/10.1071/WR09030.

Garel, M., Cugnasse, J.M., Hewison, A.M., Maillard, D., 2006. Errors in age determination of mouflon in the field. Wildl. Soc. Bull. 34, 300-306. http://dx.doi.org/10.2193/00917648(2006)34

Gipson, P., Ballard, W., Nowak, R., Mech, L., 2000. Accuracy and precision of estimating age of gray wolves by tooth wear. J. Wildl. Manag. 64, 752-758.

Groom, R.J., Funston, P.J., Mandisodza, R., 2014. Surveys of lions Panthera leo in protected areas in Zimbabwe yield disturbing results: what is driving the population collapse? Oryx 48, 385-393. http://dx.doi.org/10.1017/S0030605312001457.

Hiller, T., 2014. Comparison of two age-estimation techniques for cougars. Northwest. Nat. 95, 77-82.

Hoefs, M., Konig, R., 1984. Reliability of aging old dall sheep ewes by the horn annulus technique. J. Wildl. Manag. 48, 980-982.

IUCN, UNEP-WCMC, 2015. The World Database on Protected Areas (WDPA). www. protectedplanet.net (accessed 10.1.15)

Jarvis, A., Reuter, H., Nelson, A., Guevara, E., 2008. Hole-filled SRTM for the Globe Version 4. CGIAR-CSI SRTM $90 \mathrm{~m}$ Database.

Johnson, P.C.D., 2014. Extension of Nakagawa \& Schielzeth's $R^{2}$ GLMM to random slopes models. Methods Ecol Evol. 5, 944-946. http://dx doi.org/10.1111/2041-210X.12225.

Kays, R.W., Patterson, B.D., 2002. Mane variation in African lions and its social correlates. Can. J. Zool. 80, 471-478. http://dx.doi.org/10.1139/z02-024.

Keehner, J.R., Wielgus, R.B., Maletzke, B.T., Swanson, M.E., 2015. Effects of male targeted harvest regime on sexual segregation in mountain lion. Biol. Conserv. 192, 42-47. http://dx.doi.org/10.1016/j.biocon.2015.09.005.

Kottek, M., Grieser, J., Beck, C., Rudolf, B., Rubel, F., 2006. World map of the Köppen-Geiger climate classification updated. Meteorol. Z. 15, 259-263. http://dx.doi.org/10.1127/ 0941-2948/2006/0130.

Lindsey, P.A., Balme, G.A., Booth, V.R., Midlane, N., 2012. The significance of African lions for the financial viability of trophy hunting and the maintenance of wild land. PLoS One 7. http://dx.doi.org/10.1371/journal.pone.0029332.

Lindsey, P.A., Balme, G.A., Funston, P.J., Henschel, P., Hunter, L.T.B., 2016. Life after Cecil: channeling global outrage into funding for conservation in Africa. Conserv. Lett. 0, 1-5. doi:http://dx doi.org/10.1007/s13398-014-0173-7.2

Lindsey, P.A., Balme, G.A., Funston, P.J., Henschel, P., Hunter, L.T.B., Madzikanda, H., Midlane, N., Nyirenda, V., 2013. The trophy hunting of African lions: scale, current management practices and factors undermining sustainability. PLoS One 8, 1-11. http://dx.doi.org/10.1371/journal.pone.0073808.

Lindsey, P.A., Roulet, P.A., Romañach, S.S., 2007. Economic and conservation significance of the trophy hunting industry in sub-Saharan Africa. Biol. Conserv. 134, 455-469. http://dx.doi.org/10.1016/j.biocon.2006.09.005.
Loehr, J., Carey, J., Ylönen, H., Suhonen, J., 2008. Coat darkness is associated with social dominance and mating behaviour in a mountain sheep hybrid lineage. Anim. Behav. 76, 1545-1553. http://dx.doi.org/10.1016/j.anbehav.2008.07.012.

Loveridge, A.J., Searle, A.W., Murindagomo, F., Macdonald, D.W., 2007. The impact of sport-hunting on the population dynamics of an African lion population in a protected area. Biol. Conserv. 134, 548-558. http://dx.doi.org/10.1016/j.biocon. 2006.09.010.

Lundervold, M., Langvatn, R., 2003. A comparison of age estimation methods for the saiga antelope Saiga tatarica. Wildl. Biol. 9, 219-227.

Mandisodza, R., Lindsey, P.A., Funston, P.J., Loveridge, A.J., 2009. Lion Aging and Adaptive Quota Management: The Application of the Points System in Zimbabwe in 2014. Zimbabwe.

Milman, O., 2015. Australia bans hunting "trophies" from lions entering or leaving the country. Guard 12-13.

Milner-Gulland, E.J., Nilsen, E.B., Andreassen, H.P., 2007. Demographic side effects of selective hunting in ungulates and carnivores. Conserv. Biol. 21, 36-47.

Naidoo, R., Weaver, L.C., Diggle, R.W., Matongo, G., Stuart-Hill, G., Thouless, C., 2016. Complementary benefits of tourism and hunting to communal conservancies in Namibia. Conserv. Biol. 30, 628-638. http://dx.doi.org/10.1111/cobi.12643.

Packer, C., 2001. Infanticide is no fallacy. Am. Anthropol. 102, 829-857.

Packer, C., Brink, H., Kissui, B.M., Maliti, H., Kushnir, H., Caro, T., 2011. Effects of trophy hunting on lion and leopard populations in Tanzania. Conserv. Biol. 25, 142-153. http://dx.doi.org/10.1111/j.1523-1739.2010.01576.x.

Packer, C., Kosmala, M., Cooley, H.S., Brink, H., Pintea, L., Garshelis, D., Purchase, G., Strauss, M., Swanson, A., Balme, G.A., Hunter, L.T.B., Nowell, K., 2009. Sport hunting, predator control and conservation of large carnivores. PLoS One 4, e5941. http://dx.doi.org/10. 1371/journal.pone.0005941

Packer, C., Pusey, A.E., 1993. Should a lion change its spots? Nature http://dx.doi.org/10 1038/362595a0.

Patterson, B.D., Kays, R.W., Kasiki, S.M., Sebestyen, V.M., 2006. Developmental effects of climate on the lion's mane (Panthera leo). J. Mammal. 87, 193-200. http://dx.doi. org/10.1644/05-MAMM-A-226R2.1.

Pitman, R.T., Swanepoel, L.H., Hunter, L.T.B., Slotow, R., Balme, G.A., 2015. The importance of refugia, ecological traps and scale for large carnivore management. Biodivers. Conserv. http://dx.doi.org/10.1007/s10531-015-0921-9.

Pusey, A.E., Packer, C., 1994. Non-offspring nursing in social carnivores: minimizing the costs. Behav. Ecol. http://dx.doi.org/10.1093/beheco/5.4.362.

Development Core Team, R., 2008. R: A Language and Environment for Statistical Computing. Vienna, Austria.

Riggio, J., Jacobson, A., Dollar, L., Bauer, H., Becker, M.S., Dickman, A.J., Funston, P.J., Groom, R., Henschel, P., de Iongh, H., Lichtenfeld, L., Pimm, S., 2012. The size of savannah Africa: A lion's (Panthera leo) view. Biodivers. Conserv. 22, 17-35. http://dx.doi.org/10. 1007/s10531-012-0381-4.

Rodríguez-Muñoz, R., del Valle, C.R., Bañuelos, M.J., Mirol, P., 2015. Revealing the consequences of male-biased trophy hunting on the maintenance of genetic variation. Conserv. Genet. 16, 1375-1394. http://dx.doi.org/10.1007/s10592-015-0747-8.

Rosenblatt, E., Becker, M.S., Creel, S., Droge, E., Mweetwa, T., Schuette, P.A., Watson, F., Merkle, J., Mwape, H., 2014. Detecting declines of apex carnivores and evaluating their causes: an example with Zambian lions. Biol. Conserv. 180, 176-186. http:// dx.doi.org/10.1016/j.biocon.2014.10.006.

Schaller, G.B., 1972. The Serengeti Lion: A Study of Predator-prey Relations. University of Chicago Press, Chicago.

Selier, S.A.J., Page, B.R., Vanak, A.T., Slotow, R., 2014. Sustainability of elephant hunting across international borders in southern Africa: A case study of the greate Mapungubwe Transfrontier conservation area. J. Wildl. Manag. 78, 122-132. http:// dx.doi.org/10.1002/jwmg.641.

Skalski, J., Ryding, K., Millspaugh, J., 2005. Wildlife Demography: Analysis of Sex, Age, and Count Data. Elsevier Inc., Burlington, MA.

Smuts, G.L., 1980. Comparative growth of wild male and female lions (panthera leo.pdf).

Smuts, G.L., Anderson, J.L., Austin, J., 1978. Age determination of the African lion. J. Zool. $185,115-146$.

U.S. Fish and Wildlife Service, 2015. Endangered and threatened wildlife and plants; listing two lion subspecies. Fed. Regist. 80, 80000-80056.

Van Horn, R.C., McElhinny, T.L., Holekamp, K.E., 2003. Age estimation and dispersal in the spotted hyena (Crocuta crocuta). J. Mammal. 84, 1019-1030. http://dx.doi.org/10. 1644/BBa-023.

Vaughan, A., 2015. France Bans Imports of Lion Hunt Trophies Considers Stricter Controls on Other Species 1-2.

West, P.M., MacCormick, H., Hopcraft, G., Whitman, K.L., Ericson, M., Hordinsky, M., Packer, C., 2006. Wounding, mortality and mane morphology in African lions, Panthera leo. Anim. Behav. 71, 609-619. http://dx.doi.org/10.1016/j.anbehav.2005. 06.009.

West, P.M., Packer, C., 2002. Sexual selection, temperature, and the lion's mane. Science 297, 1339-1343. http://dx.doi.org/10.1126/science.1073257.

Whitman, K.L., 2010. Pocket Guide to Aging Lions. Conservation Force.

Whitman, K.L., Packer, C., 2007. A Hunter's Guide to Aging Lions in Eastern and Southern Africa. Safari Press, Long Beach, California.

Whitman, K.L., Starfield, A.M., Quadling, H., Packer, C., 2007. Modeling the effects of trophy selection and environmental disturbance on a simulated population of African lions. Conserv. Biol. 21, 591-601. http://dx.doi.org/10.1111/j.1523-1739.2007. 00700.x.

Whitman, K.L., Starfield, A.M., Quadling, H.S., Packer, C., 2004. Sustainable trophy hunting of African lions. Nature 428, 175-178. http://dx.doi.org/10.1038/nature02395.

Wildlife Division, 2012. Comment on ESA Status Review of the African Lion. Tanzania. 